\title{
Foresters' ethics
}

\author{
by Ian S. Moss, R.P.F.
}

\section{Introduction}

This article is written in response to the proposed codes of ethics and principles recently submitted to sections of the Canadian Institute of Forestry (CIF) by the national office. The information provided to the sections was prepared in consultation with the Canadian Council of Professional Foresters and the CIF.

The proposed code of principles evoked the possibility of conflict, for example, between the necessity for: preserving biodiversity and denouncing any abuse against forest ecosystems on one hand versus the commitment to protect against harmful agents to perpetuate the usefulness of forests and to enhance their value to society (a utilitarian perspective) on the other hand. The ethical principle necessary for resolving potential conflicts was not made clear although sustained yield and sustainable development of all resources (excluding non-resources?) were described. After reviewing the proposed code of ethics and principles in a CIF Cariboo Section meeting, it was concluded that all of the necessary ingredients were put forth, but they were not placed in a context that would provide a sufficiently unified direction for all foresters, and that severe conflict between foresters could result.

Therefor, a second statement of ethics was introduced for discussion and is provided herein. The recommended ethical statement was produced after defining the formal conditions necessary for establishing a valid code of ethics and principles; these conditions are also described herein. Before dealing with these issues however, it is useful to understand why we require ethics in the first place.

Morality is the intervenor between the realization of our fears and desires. For example, our desire to consume is offset by our fear of death, ultimately a result of living itself. In today's terms, the necessity for maintaining biodiversity is born out of a fear that by diminishing it to some unknown extent we could cause our own destruction. On the other hand, we have a desperate need to consume more resources just to eke out a bare existence in many parts of the world; this is being exacerbated by an exploding global population. Therefor, ethical statements are moral commitments regarding how we will conduct ourselves in our daily activities so that we may mitigate against, if not completely avoid, the realization of our fears and yet meet our needs and desires.

With this perspective, the formal conditions necessary for a valid ethical statement are outlined herein and statements of ethical principles and practices are recommended.

\footnotetext{
'From P.W. Taylor (1986). The respect for nature. Princeton University Press. Princeton, New Jersey, USA.

2 ...giving equal weight to every person's value system and at the same time making it possible for each to pursue the realization of his or her own valuesystem in ways compatible with everyone else's similar pursuit.

${ }^{3}$ One who takes the attitude of respect toward individual organisms, species populations, and biotic communities of the Earth's natural ecosystems and regards those entities and groups of entities as possessing inherent worth, in the sense that their value or worth does not depend on their being valued for their usefulness in furthering human ends (or the ends of any other species).
}

\section{Conditions for Valid Moral Principles ${ }^{1}$}

The conditions that any rule or standard must satisfy, if it is to be included in a normative (as opposed to conceptual) ethical system that can be correctly said to be valid, are outlined below. By "valid" it is meant that the rules and standards of the system are in truth binding upon all moral agents.

There are two types of conditions. "The formal conditions", which are now widely accepted in contemporary ethics, may be thought of as defining what is meant by describing or classifying a rule, standard, or principle as a moral one, that is, as belonging to the category of morality or ethics. Material conditions define the fundamental attitude that gives rise to rules, standards or principles. Human ethics generally rely on an attitude of respect for persons ${ }^{2}$, and environmental ethics on respect for nature ${ }^{3}$. These attitudes towards people and nature are adopted based on a rational system of beliefs, where possible founded on scientific descriptions of man and nature. The separation of the two kinds of ethics depends in part on whether or not man is seen as part of nature, indicating a predisposition toward an acceptance of both human and environmental ethics, or separate from it, indicating an acceptance of human ethics only.

All of the following Formal conditions must be met to establish a valid ethical system:

General in form: A rule or standard is general in form when it does not contain any reference to particular persons or actions, but only mentions the kinds of things in terms of their properties. For example, we should allow others to express their opinions freely. Thus a valid moral rule never states that a specific individual or group must perform a certain action at a certain time and place. It simply states that a kind of action must be done by anyone (who is a moral agent) in certain generally described circumstances.

Universal applicability amongst all moral agents: A valid moral rule or standard must be a normative principle that can be applied universally to all beings who are moral agents, and it must be conceived to be universally applicable to those who subscribe to it as a valid binding moral norm.

Applied disinterestedly: If a rule or standard is a valid moral norm, it is subscribed to as a principle that is to be followed by each agent independently of that agent's particular ends and interests.

Advocated: The principles must be advocated for all to adopt. Hence, foresters should adopt principles, rules and standards that (we believe) should also be adopted by those outside the profession, as if they were also in the position of discharging the same responsibilities.

Over-riding importance: The principles must be taken as over-riding all nonmoral norms. 


\section{Attitudes and Ethical Principles}

It seems best to adopt an attitude of respect for both people $^{4}$ and nature ${ }^{5}$ and to resolve conflicts through the concept of achieving sustainable development. The respect given to other people is motivated by our personal need to be accorded the same so as to realise our own potential worth; hence our agreement on the individual rights to life, freedom and happiness. The type of respect accorded to organisms, be they individuals, species populations or communities, is motivated by recognition of the following facts:

1. That we co-evolved as part of nature, not independent from it, and therefor we are dependent on it, and it on us.

2 . The potential for maintaining natural processes and functions depends on maintaining biodiversity.

3. The true value of an individual, population or community cannot be adequately assessed in utilitarian terms because every minute part of nature may hold the unforseen key to a greater realization of our own (human) potential worth in the future. From the other extreme, the loss of one individual of any given species reduces the potential for future species diversification, adaptation and survival. "Do not ask for whom the bell tolls, it tolls for thee", 6 .

If we cannot adequately comprehend the full value of nature, then it seems wise to attribute all organisms with inherent worth and to subsequently adopt an attitude of respect for them.

Accepting respect for both humanity and nature, how do we reconcile their competing requirements? Humanity needs food, shelter and water, which draws upon the space needed for the sustenance of other organisms. The challenge in this conflict is to collectively preserve our potential options for future development without significantly diminishing the value and joys of our individual existences in the short term. The challenge is to determine the limits to which resources can be reaped while at the same time preserving biodiversity, an icon of hope for a future in which all organisms can continue to flourish.

Society must choose how best to balance this fear of mutual (humanity and nature) destruction with the desire to survive and prosper through a selection from alternative uses of land - perhaps an allocation to single use (fibre) farming for secure provision of supplies, to nature reserves (roadless wilderness) for securing the potential survival and growth (realization of inherent worth) of other organisms with minimal human interference, and to integrated management for balancing the satisfaction of our short term requirements (supplies) with the avoidance of long term fears (loss of biodiversity) on ever-smaller parcels of land.

No one individual or sector of society is capable of striking the proper balance in such decisions. If we survive and prosper, we do so as a group. If we become weak and diminished, we do so as a group. Therefor, Foresters must recognise that our first responsibility is to assist society in making the difficult decisions necessary to achieve and maintain sustainable development. Our second responsibility is to apply the decisions in accordance with society's wishes. As Foresters we are, first and foremost, beholden to society

\footnotetext{
4 ...we respect the needs of society as defined by society.

5 ...we acknowledge the inherent worth of organisms, populations and ecosystems and therefor seek to protect them.

${ }^{6} \mathrm{E}$. Hemingway. For whom the bell tolls.
}

for the trust that has been placed in us to manage forests on its behalf, according to its requirements.

\section{Practices}

One might ask who speaks for society? Who provides the direction and mandate necessary to enable us to fulfil our responsibilities? It is our elected officials. Our elected officials set the ground rules for decision-making through legislation and are often asked to make the final determination of what should, and should not, be done. These decisions are usually based on recommendations produced through implementation of planning processes, judicial hearings, commissions, review panels, etc., and agreed to through negotiation and compromise, and finally, sanctioned through the ballot box.

The Professional ${ }^{7}$ Forester's role in these processes is as a servant to society. As servants to society we can advise of the range of feasible management alternatives and of the consequences of implementing any one of them, but like lawyers and doctors on the issues of practising abortion and euthanasia, we cannot make the ultimate decision unless we were specifically asked to do so (by society). However, it is more likely that we be asked for our recommendations. Foresters should strive to become the honest broker in the processes of developing land use strategies and prescriptions.

The Forester's commitment to sustainable development through our attitudes toward humanity and nature may take precedence over all other commitments when making recommendations regarding changes to legislation, regulations or other policies and procedures. However, we must always make clear any potential contradictions or conflicts with prevailing legislation that may be explicit or implicit in our recommendations. Regardless of such recommendations, our duty to fulfil (implement) society's legislated mandate must always take precedence when the proposed activities are intended for operational application. Formal management documents such as Timber Supply Area, Management Working or Operating Plans, Statements of Audit or Prescriptions must always be prepared in both form and substance consistent with the prevailing legislation. Recommendations contrary to legislation may be enclosed in such documents in the form of a letter or presented separately as a proposal to the proper authorities.

With respect to any recommendations to pursue particular courses of action, we must always strive to fully understand the basis for any stated positions that may be contrary or consistent with our recommendations. We should acknowledge those recommendations that conform with our principle of sustainable development and that are based on sound logic with an adequate accounting of legitimate factual information; we should refute those that do not conform or are not based as such.

In all matters, both public and private, Foresters should act in a manner that will not discredit the Profession, that will maintain the confidentiality of business with our employers and clients, that is courteous toward other members of the Profession and Society, and that is in keeping with our primary role as servants to society.

\footnotetext{
${ }^{7}$ Craig Farnden, 1991. Personal communication. Cariboo Section of the CIF. Prince George, B.C.
} 
How then, in practice, should we properly advise our clients, employers, elected officials or their designated representatives, given our attitudes toward humanity and nature itself and our commitments to society and the principle of sustainable development? We must reap the resources to satisfy our needs in the short term, but we must not harvest too much or in such a way as to jeopardize our existence or that of nature itself in the longer term. As Foresters we must strive to apply within our ethical framework all of the scientific knowledge we have at our disposal in advising society of the short term gains and long term consequences of implementing alternative land use strategies and prescriptions. We should recommend the options that have the greatest (short term) benefits for the least (long term) costs, but we should be humble about our ability to quantify the trade-offs given the complexities of nature and an unknown future. We must be aware of potential values or risks to values that may have been overlooked in land use planning processes and subsequently make appropriate recommendations to the proper authorities, be it the need to protect the forest from bark beetle infestations through harvesting or the need to protect critical species' habitat by not harvesting. When charged with implementing decisions on the landscape, we must do so in a manner consistent with society's wishes, but we must recommend otherwise when practices that have been deemed unacceptable (through guidelines, for example) would in fact be preferable given: society's overall intentions (as indicated through its' adopted statutes), our attitudes towards nature and humanity, and the necessity for achieving and maintaining sustainable development. albeit we may disagree with regard to the appropriate solution of how to achieve and maintain sustainable development. Through respect for other foresters and all members of society we can benefit from disagreement in our search for the truth. "Error is indeed our enemy, but it alone points to the truth and therefor deserves our respectful treatment ${ }^{\prime \prime}$. Therefor the common cause should carry us beyond the rhetoric, toward our search for a better understanding of the world within and around us. By adopting this ethical point of view and offering it as a model for others to follow, I believe that Foresters will be taking a leadership role in addressing today's serious social, economic and environmental issues. This ethical stance will hopefully have an enduring and positive impact on our local and global environments and economies.

At the very least, Foresters must take an orderly approach to the development of the codes of ethics, principles, standards and practices. We should attempt to meet the formal conditions for establishing a valid ethical position and should agree on its substance. We must be clear about why we have adopted certain ethical attitudes and principles, as I have tried to do here, if we expect these to be adhered to by our membership and to be acknowledged by our employers and society at large. Ultimately, we should use the normative code of ethics to unite Foresters, Biologists, Technicians and all members of society alike, in the pursuit of our common cause.

${ }^{8}$ From Allan Bloom, 1987. The closing of the American mind. Simon and Schuster, Toronto.

\section{Conclusion}

The ethical principles and practices enunciated above provide an opportunity to unite Foresters in a common cause

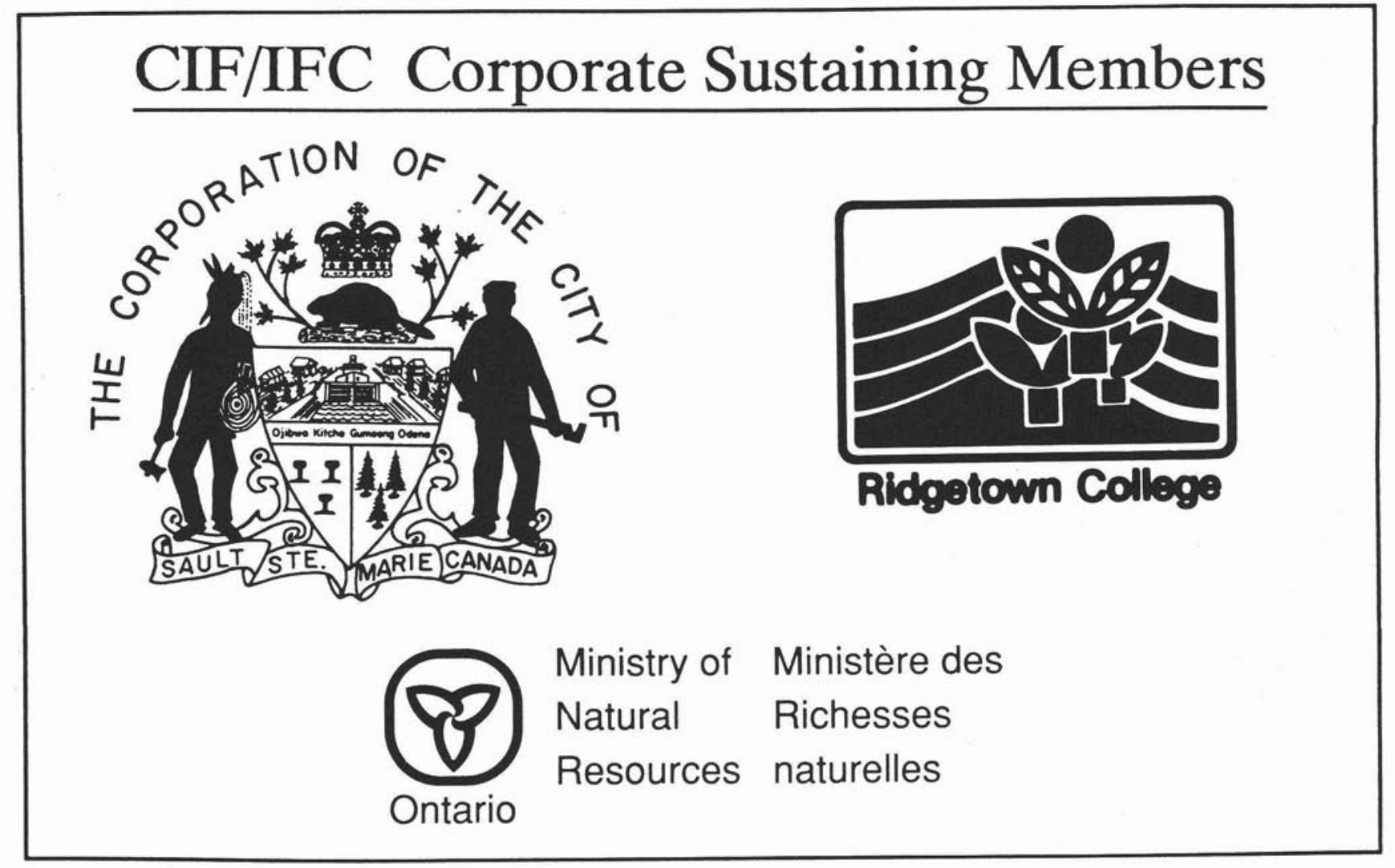

